\title{
竞 \\ Perspectivas do uso de fitoterápicos no tratamento do sêmen caprino infectado pelo vírus da Artrite Encefalite Caprina
}

\author{
[Prospectives of herbal remedies in the treatment of caprine semen infected by Caprine Arthritis \\ Encephalitis virus]
}

\section{"Revisão/Review"}

\author{
Renato Mesquita Peixoto $^{1 *}$, Maria Fátima da Silva Teixeira ${ }^{1}$,
} Alice Andrioli ${ }^{2}$, Raymundo Rizaldo Pinheiro ${ }^{2}$, Antonio Adailson de Sousa Silva ${ }^{3}$, Tereza Dávila de Freitas Aguiar ${ }^{1}$, Dalva Alana Aragão de Azevedo ${ }^{1}$, Ana Lídia Madeira de Sousa ${ }^{1}$

\author{
${ }^{1}$ Laboratório de Virologia, Programa de Pós-Graduação em Ciências Veterinárias, Universidade Estadual do Ceará, \\ Fortaleza-CE, Brasil. \\ ${ }^{2}$ Embrapa Caprinos e Ovinos, Sobral-CE, Brasil. \\ ${ }^{3}$ Departamento de Fisiologia e Farmacologia, Universidade Federal do Ceará, Fortaleza-CE, Brasil. \\ *Autor para correspondência/Corresponding author: E-mail: renatomiraima@gmail.com
}

\begin{abstract}
Resumo
A transmissão da artrite encefalite caprina pelo sêmen inviabiliza o uso de reprodutores soropositivos de alto valor genético. Como o vírus da artrite encefalite caprina (CAEV), é encontrado no sêmen na forma de RNA viral (vírus livre) ou DNA pró-viral dentro das células não espermáticas, possibilita que pesquisas com plantas com potencial antiviral sejam algo promissor para viabilizar o sêmen de reprodutores caprinos de grande valor zootécnico infectados. Diante disso, com essa revisão objetivou-se elucidar o potencial de fitocompostos, com comprovada ação antiviral, que poderiam vir a ser alvo de estudo para inativar o lentivírus caprino no sêmen. Inúmeras plantas de muitas famílias botânicas já foram estudadas para validação de efeito antiviral contra diversos vírus que acometem animais e humanos. Folhas, raízes, flores, e sementes demonstraram ao longo do tempo em sua constituição fitoquímica substâncias antivirais promissoras. De acordo com o tipo de planta, não apenas algumas partes dela, mas regiões inteiras da mesma são alvos das pesquisas por fitocompostos a ser usado como alternativa no combate as doenças virais. A base dos estudos nessa vertente são os metabólitos secundários, pois nas pesquisas têm apresentado compostos bioativos antivirais de alto potencial atuando nas diferentes fases do ciclo de desenvolvimento viral. Dessa forma, a biodiversidade da flora brasileira aliada à tendência de formar fitocompostos poderiam contribuir no avanço das pesquisas, a fim de encontrar uma alternativa de base natural, potencialmente eficaz, para eliminar os riscos de transmissão do CAEV pelo sêmen.
\end{abstract}

Palavras-chave: antiviral; caprinos; extrato de plantas; produtos naturais; retrovirose.

\begin{abstract}
The transmission of Caprine Arthritis Encephalitis in semen limits the use of seropositive bucks that have high genetic value. The Caprine Arthritis Encephalitis virus (CAEV) may be found in the form of RNA virus (free virus) or pro-viral DNA within non-spermatic cells in semen. Thus, researches involving plants with potential antiviral activity are promising for developing techniques that allow the use of semen from high-quality production goats that are infected by this virus. Therefore, this review aimed to elucidate the potential of phytocompounds that have known antiviral activity and could be used in studies to assess inactivation of the caprine lentivirus in semen. Several plants from many botanical families have been tested for validation of antiviral effect against viruses that infect animals and humans. Leaves, roots, flowers and seeds have demonstrated promising antiviral substances in their phytochemical composition. According to the type of plant, entire regions of the specimens are used for researching phytocompounds that can serve as alternatives in the treatment of viral diseases. Most of the studies involving this subject focus on secondary metabolites and several have identified high potential compounds with bioactive antiviral activity in different stages of the viral development cycle. Hence, the biodiversity of Brazilian flora, which has a tendency for phytocompound
\end{abstract}


formation, provides adequate material for research aimed at finding a natural alternative to eliminate the risk of CAEV transmission through semen.

Keywords: antiviral; caprine; plant extract; natural products; retrovirus.

\section{Introdução}

As infecções virais estão entre as principais causas de enfermidades que acometem humanos e animais, sendo que muitas ainda permanecem com a inexistência de tratamento, ou ocasionadas por vírus que desenvolveram certa resistência aos medicamentos antivirais tradicionais (Bagla et al., 2012). Dentre essas enfermidades está à artrite encefalite caprina (CAE), a qual é ocasionada por um vírus de ácido ribonucleico (RNA) pertencente ao gênero Lentivirus, família Retroviridae (Minguijón et al., 2015; ICTV, 2017) que se caracteriza por ampla variabilidade genética, e com capacidade de ser transmitido pelo uso de sêmen contaminado, tanto via inseminação artificial quanto no acasalamento (Souza et al., 2013; Turchetti et al., 2013).

A transmissão do vírus da artrite encefalite caprina (CAEV) via sêmen, inviabiliza o uso de reprodutores soropositivos de alto valor genético, trazendo restrições ao uso de biotecnologias reprodutivas (Cortez-Romero et al., 2013). Adicionalmente, a presença deste em fluidos e secreções, na forma de RNA viral (vírus livre) ou ácido desoxirribonucleico (DNA) pró-viral, dentro das células não espermáticas existentes no sêmen, preconizam a utilização de técnicas de lavagem como swim-up e centrifugação em gradiente de Percoll, visando separar os espermatozoides do plasma seminal de animais infectados. Entretanto, essas técnicas não eliminam o vírus e realizam apenas a redução da carga viral do patógeno (Peterson et al., 2008; Ávila et al., 2015).

Dessa forma, por não existir ainda um tratamento eficaz no combate ao lentivírus caprino, e nenhuma vacina disponível no mercado (Tu et al., 2017), se faz necessário a busca por métodos alternativos potencialmente capazes de serem usados no combate a esse vírus. Dentro dessa premissa, produtos a base de plantas com inúmeras atividades biológicas apresentam-se promissores para o desenvolvimento de compostos antivirais (Rebensburg et al., 2016) capazes de inativar o vírus no sêmen, viabilizando o melhor uso de reprodutores de alto valor genético, porém portadores do CAEV. Portanto, o objetivo da presente revisão é elucidar o potencial de fitocompostos, com comprovada ação antiviral, que poderiam vir a ser alvo de estudo para inativar o lentivírus caprino no sêmen.

\section{Presença do lentivírus caprino no sêmen e sítios de ação antirretroviral}

O sistema monocítico-fagocitário preferencialmente é o local onde ocorre a infecção pelo lentivírus caprino, acarretando uma infecção estável, sem lise celular, e cujo estado de maturação das células determina a expressão do genoma viral (Tu et al., 2017). Além disso, o processo replicativo, conduzido pela transcriptase reversa, caracteriza-se por altas taxas de mutação que acarreta uma ampla diversidade genética (L'Homme et al., 2015).

No ejaculado, os leucócitos são as principais células portadoras do vírus na forma de DNA próviral, com a infecção sendo originada da presença dos vírus nos testículos, epidídimo, e glândulas acessórias (Al Ahmad et al., 2008; Lamara et al., 2013; Souza et al, 2014), porém a presença dele na sua forma livre também já foi relatada (Peterson et al., 2008). No que diz respeito ao espermatozoide, Ricarte et al. (2010) avaliando a ocorrência de lentivírus caprino em espermatozoides, pelo teste de imunohistoquímica, obtiveram positividade para a proteína p28 do CAEV, mas na microscopia eletrônica o vírus foi observado somente na peça intermediária.

Alguns estudos ainda demonstraram que a presença do vírus no sêmen é intermitente e que sua presença tende a ser maior quando ocorre algum processo inflamatório na região genital do animal (Travassos et al., 1999; Cortez-Romero et al., 2013). Mas mesmo assim, a presença desse patógeno no sêmen não interfere nos parâmetros seminais que são condizentes com os desejáveis para a espécie caprina (Paula et al., 2009; CBRA, 2013).

Entretanto, como forma de evitar a transmissão do vírus, em geral, o recomendado é a retirada do reprodutor do plantel, restringindo a sua utilização como doador de esperma, e dessa forma, implicando perdas econômicas, como também de material genético. Diante disso, o desenvolvimento de produtos com potencial antiviral além de 
inativar o vírus no ejaculado, poderia permitir a volta à atividade reprodutiva desses animais.

A maioria dos retrovírus e, entre eles o lentivírus caprino, estão incluídos em um grupo de grande heterogeneidade e de alta capacidade de mutação, resultando em elevada variabilidade genética (Minguijón et al., 2015). Desse modo, tratamentos que visem o combate à enfermidade de origem retrovírica devem ser embasados no emprego de substâncias que apresentem potencial de impedir a síntese de RNA (Dan e Castellar, 2015). A replicação dos retrovírus na célula hospedeira depende necessariamente da transcriptase reversa, integrasse e protease (Kenyon e Lever, 2011), porém a transcriptase reversa e a integrase são os principais alvos na busca por antivirais, por serem enzimas fundamentais ao longo do processo replicativo retroviral ( $\mathrm{Gu}$ et al., 2016). Mas inibidores de protease também podem ser levados em consideração nas pesquisas por antivirais advindos de produtos naturais, pois como ela transforma proteínas estruturais em enzimas virais a partir da clivagem de poliproteínas, uma vez que esse processo é inibido, consequentemente essas poliproteínas não serão clivadas determinando a formação apenas de vírions não infecciosos (Silva et al., 2016).

Assim, os sítios de ação de um antirretroviral são voltados a todo o processo de replicação do vírus, pois como os mesmos necessariamente precisam estar infectando uma célula hospedeira para poder se desenvolver, métodos que possibilite inibir a fixação e entrada deste no organismo, funcionaria como uma medida de prevenção que viria a limitar a disseminação do vírus pelo organismo (Yeh e Coen, 2011). Desse modo, os fitoterápicos com potencial efeito antiviral devem apresentar a capacidade de atuar nas diversas etapas por meio do qual o vírus exerce sua replicação, e preferencialmente inibir a transcriptase reversa e atingir a produção de ácidos nucleicos, bem como de proteínas sintetizadas pelo próprio vírus e não as do hospedeiro (Ministério da Saúde, 2008).

\section{Produtos naturais com potencial antiviral}

A utilização de plantas medicinais com indício de atividade antiviral tem sido estudada ao longo do tempo, tendo como base distintas plantas das mais variadas famílias botânicas (Tabela 1). A ampla maioria dessas pesquisas tem como intuito validar os princípios ativos dessas plantas e aperfeiçoar o seu uso prático no combate as retroviroses, principalmente direcionadas contra os lentivírus de primatas, incluindo principalmente o ser humano (Zhang et al., 2017). Diante disso, a busca por substâncias antivirais, tem visto nos produtos a base de plantas uma rica fonte por meio do qual é possível conseguir fitocompostos com ação potencial contra as mais diversas enfermidades de origem viral. E, ao longo do tempo, evidencia-se que inúmeras plantas das mais variadas famílias botânicas, vem demonstrando uma interação com as etapas que compõem o ciclo viral (Lin et al., 2014).

Muitas das pesquisas por métodos alternativos antirretroviral iniciaram em virtude da preocupação com a elevação dos índices de infecção pelo vírus da imunodeficiência humana (HIV), vírus esse similar ao lentivírus caprino, que embora não consiga eliminar completamente o vírus apresenta tratamento considerado eficaz. Entretanto, as desvantagens acarretadas ao longo da terapia antirretroviral relacionados ao HIV, principalmente casos de resistência aos atuais medicamentos, levantou a necessidade de desenvolver métodos alternativos e com alto teor de eficácia (Prinsloo et al., 2017). Dessa forma, 144 famílias botânicas já foram testadas e vieram a apresentar efeito antiviral contra o HIV, sendo que a família Asteraceae é a que detém o maior número de espécies testadas, entretanto grande parte dessas pesquisas não conseguiram isolar e determinar com clareza o mecanismo de ação do potencial efeito antiviral (Dan e Castellar, 2015).

Dentro dessa concepção, Zhang et al., (2017) avaliando extrato aquoso de Phyllanthus urinaria, uma Euphorbiaceae, detectaram a eficácia antiviral do mesmo, o qual interagindo com a transcriptase reversa conseguiu inibir a entrada do HIV nas células. Já Shikalepo et al., (2017) em ensaios in vitro evidenciaram que extratos etanólicos da parte de Bulbine frutescens pertencente a Família Asphodelaceae apresentaram atividade inibitória contra a protease do HIV, bem como a transcriptase reversa e a integrasse, chegando a atingir de 50 a $87 \%$ de inibição viral dependendo da concentração. Além do uso de uma planta específica denota-se ainda que misturas de plantas advindas de famílias botânicas distintas (Asteraceae, Bignoniaceae, Fabaceae e Myrtaceae) foram alvo das pesquisas de Mophuting et al., (2017) os quais observaram que os extratos hexânicos originados dessa mistura de ervas demonstrou potencial inibitório contra a 
transcriptase reversa do HIV e restringiu sua replicação.

Apesar de grande parte das pesquisas serem direcionadas ao HIV, outros vírus também causadores de importantes enfermidades, já tiveram fitocompostos sendo descritos como potencial inibidor, tais como: poliovírus tipo 1
(Faccin-Galhardi et al., 2012); vírus da enterite de patos (Song et al., 2013); vírus da doença de Newcastle (Song et al., 2015); vírus H1N1 (Bang et al., 2016; Ha et al., 2016); parvovírus canino (Feng et al., 2017); vírus da hepatite A (Seo et al., 2017) e herpes vírus tipo 1 (Twilley et al., 2017).

Tabela 1. Plantas medicinais de distintas famílias botânicas com atividade antiviral testada.

\begin{tabular}{|c|c|c|c|c|c|c|c|c|}
\hline Planta & Família Botânica & $\begin{array}{l}\text { Parte da Planta } \\
\text { Utilizada }\end{array}$ & $\begin{array}{l}\text { Tipo de } \\
\text { Extrato }\end{array}$ & $\begin{array}{l}\text { Principal composto } \\
\text { fitoquímico }\end{array}$ & Vírus & $\mu \mathrm{g} / \mathrm{mL}$ & Sítio de Ação & Referência \\
\hline Sesbania grandiflora & Fabaceae & Flores & Etanólico & Flavonoides & $\begin{array}{l}\text { Herpes simples } \\
1 \mathrm{e} 2\end{array}$ & 20 a 45 & $\begin{array}{c}\text { Replicação do vírus e } \\
\text { atividade imunomoduladora }\end{array}$ & Arthanari et al. (2012) \\
\hline Podocarpus henkelii & Podocarpaceae & Folhas & Etanólico & $\begin{array}{l}\text { Biflavones, } \\
\text { terpenoides e } \\
\text { dilactonas }\end{array}$ & $\begin{array}{l}\text { Cinomose Canina e } \\
\text { Doença da Pele } \\
\text { Grumosa }\end{array}$ & 3,0 & Replicação do vírus & Bagla et al. (2012) \\
\hline Avicennia marina & Acanthaceae & Folhas & Etanólico & $\begin{array}{l}\text { Flavonoides, fenol e } \\
\text { taninos }\end{array}$ & $\begin{array}{l}\text { Vírus da } \\
\text { Imunodeficiência } \\
\text { Humana (HIV) }\end{array}$ & 372 a 489 & $\begin{array}{l}\text { Transcriptase Reversa e } \\
\text { DNA polimerase }\end{array}$ & Beula et al. (2012) \\
\hline Melia azedarach & Meliaceae & Folhas & Etanólico & Flavonoides & $\underset{1}{\text { Herpes Simples Tipo }}$ & 62,5 & Transcrição Viral & Bueno et al. (2012) \\
\hline Azadirachta indica & Meliaceae & Folhas & Aquoso & Arabinose e galactose & Poliovírus tipo 1 & $12,1 \mathrm{a} 80$ & Replicação Viral & Faccin-Galhardi et al. (2012) \\
\hline Alpinia katsumadai & Zingiberaceae & Sementes & Etanólico & Flavonoides & $\begin{array}{l}\text { Rotavírus bovino e } \\
\text { suíno } \\
\text { Vírus da }\end{array}$ & 7 a 33,7 & Adsorção viral & Kim et al. (2012) \\
\hline Plectranthus barbatus & Lamiaceae & Folhas & Etanólico & Diterpenoides & $\begin{array}{l}\text { Imunodeficiê̂ncia } \\
\text { Humana (HIV) }\end{array}$ & 62 & Inibição da protease & Kapewangolo et al. (2013) \\
\hline Cinnamomum cassia & Lauraceae & Galhos Secos & Aquoso & - & $\begin{array}{l}\text { Vírus Sincicial } \\
\text { Respiratório } \\
\text { Humano }\end{array}$ & 30 & $\begin{array}{l}\text { Inibicĩao da ligacãão viral, } \\
\text { internalização e formação de } \\
\text { sincício }\end{array}$ & Yeh et al. (2013) \\
\hline Glycyrrhiza uralensis & Fabaceae & Fatias de Radicais & Aquoso & $\begin{array}{l}\text { Ácido glicirrízico } \\
\text { (triterpenoide) }\end{array}$ & $\begin{array}{c}\text { Enterovírus } 71 \mathrm{e} \\
\text { coxsackievirus A16 }\end{array}$ & 300 a 1000 & $\begin{array}{l}\text { Bloqueou a produção } \\
\text { infecciosa; inibiu a } \\
\text { expressão do vírus e de } \\
\text { proteína viral }\end{array}$ & Wang et al. (2013) \\
\hline Glycyrrhiza uralensis & Fabaceae & Raízes & Etanólico & $\begin{array}{l}\text { Cumarinas e } \\
\text { Triterpenóides }\end{array}$ & Vírus da Hepatite C & 20 a 80 & Replicação Viral & Adianti et al. (2014) \\
\hline Pelargonium sidoides & Geraniaceae & Raízes & Aquoso & Polifenóis & $\begin{array}{l}\text { Vírus da } \\
\text { Imunodeficiência } \\
\text { Humana (HIV) }\end{array}$ & 1,0 a 8,13 & Bloqueio de Receptores & Helfer et al. (2014) \\
\hline Bauhinia longifolia & Fabaceae & Folhas & Etanólica & Flavonoides & $\begin{array}{l}\text { Vírus da Febre } \\
\text { Mayaro }\end{array}$ & 25 a 100 & Replicação do Vírus & Santos et al. (2014) \\
\hline Aloe arborescens & Xanthorrhoeaceae & Folhas & Aquoso & - & $\begin{array}{l}\text { Vírus da Gripe } \\
\text { (H1N1; H3N2) }\end{array}$ & - & $\begin{array}{l}\text { Inibição da neuraminidase } \\
\text { (enzima viral) }\end{array}$ & Glatthaar-Saalmüller et al. (2015) \\
\hline Berberis holstii & Berberidaceae & Raízes & Aquoso & Alcaloides & $\begin{array}{l}\text { Vírus da } \\
\text { Imunodeficiê̂ncia } \\
\text { Humana (HIV) }\end{array}$ & 3,64 a 3,85 & $\begin{array}{l}\text { Inibição da Transcriptase } \\
\text { Reversa }\end{array}$ & Ngwira et al. (2015) \\
\hline Salvia plebeia & Lamiaceae & Partes Aéreas & Etanólicos & $\begin{array}{l}\text { Flavonoides e } \\
\text { Fenólicos }\end{array}$ & $\begin{array}{l}\text { Vírus da Gripe } \\
\text { (H1N1) }\end{array}$ & 20 & $\begin{array}{l}\text { Inibição da neuraminidase } \\
\text { (enzima viral) }\end{array}$ & Bang et al. (2016) \\
\hline $\begin{array}{l}\text { Cleistocalyx } \\
\text { operculatus }\end{array}$ & Myrtaceae & Folhas & Etanólico & Flavonoides & $\begin{array}{l}\text { Virus da Gripe } \\
\text { (H1N1; H9N2) }\end{array}$ & - & $\begin{array}{c}\text { Inibição da neuraminidase } \\
\text { (enzima viral) }\end{array}$ & Ha et al. (2016) \\
\hline Cistus incanus & Cistaceae & Toda a planta & Aquoso & Polifenóis & $\begin{array}{l}\text { Vírus da } \\
\text { Imunodeficiência } \\
\text { Humana (HIV) }\end{array}$ & 0,7 a 2,0 & Replicação Viral & Rebensburg et al. (2016) \\
\hline Cyathulae officinalis & Amaranthaceae & Toda a planta & Aquoso & Polissacarídeos & Parvovírus canino & - & Adsorção Viral & Feng et al. (2017) \\
\hline Peganum harmala & Zygophyllaceae & Sementes & Etanólico & Alcaloides & Vírus da Influenza A & 100 & Replicação do Vírus & Moradi et al. (2017) \\
\hline Alnus japônica & Betulaceae & Folhas & Etanólico & Flavonoides & Vírus da Hepatite A & 50 & $\begin{array}{l}\text { Inibição de Receptores } \\
\text { Virais }\end{array}$ & Seo et al. (2017) \\
\hline Bulbine frutescens & Asphodelaceae & Parte Aérea & Etanólico & Flavonoides & $\begin{array}{l}\text { Vírus da } \\
\text { Imunodeficiência } \\
\text { Humana (HIV) }\end{array}$ & 0,18 a 0,52 & $\begin{array}{l}\text { Transcriptase reversa, } \\
\text { protease e integrase }\end{array}$ & Shikalepo et al. (2017) \\
\hline Syzygium jambos & Myrtaceae & - & Etanólico & - & Herpes Vírus Tipo 1 & 50 & $\begin{array}{l}\text { Inibição de Enzima Viral } \\
\text { (COX-2) }\end{array}$ & Twilley et al. (2017) \\
\hline Phyllanthus urinaria & Euphorbiaceae & Toda a planta & Aquoso & $\begin{array}{c}\text { Ácido gálico e } \\
\text { polifenol }\end{array}$ & $\begin{array}{l}\text { Vírus da } \\
\text { Imunodeficiência } \\
\text { Humana (HIV) }\end{array}$ & 0,61 a 0,76 & Adsorção viral & Zhang et al. (2017) \\
\hline
\end{tabular}

Na literatura consultada, observou-se que o efeito antiviral de meliáceas é rotineiramente relatado, como por exemplo, Parida et al. (2002) denotaram que um extrato aquoso produzido de folhas de Azadirachta indica, determinou a total inibição da replicação do vírus da dengue, enquanto que Faccin-Galhardi et al. (2012) relataram que percentuais de até $80 \%$ de inibição viral do poliovírus tipo 1 foram conseguidos ao usar fitocomposto. Já no caso de Melia azedarach (Cinamomo) esta já apresentou resultados promissores contra o herpes vírus tipo 1 e 2 (Petrera e Coto; 2009; Bueno et al., 2012).

A expressão desse efeito antiviral no caso das meliáceas deve-se consequentemente a sua composição fitoquímica, os quais são representados nas meliáceas pelos ácidos graxos, alcaloides, esteroides, limonoides, flavonoides, taninos, saponinas e aminoácidos, pois são os principais grupos químicos encontrados em todas as polaridades de fração de extratos dessas plantas (Kumazawa et al., 2013; Al-Hashemi e Hossain, 2016)

Entretanto, efeito espermicida também já foi descrito advindo de extratos aquosos a base de folhas de Azadirachta indica (Khillare e Shrivastav, 2003), e das cinzas da madeira dessa meliácea que além de efeito espermicida gerou espermatozoides anormais, indicando que apesar de ter em sua constituição fitoquímicos potencialmente antivirais, dependendo da concentração determinará perda na qualidade espermática por interferência no processo espermatogênico (Auta e Hassan, 2016). Dessa 
forma, torna-se essencial uma avaliação criteriosa, pois a citotoxicidade de determinados constituintes presentes em uma droga natural pode acabar impedindo a descoberta de propriedades antivirais de outro componente fitoquímico (Arthanari et al., 2012).

Além de folhas e raízes, as sementes de plantas têm demonstrado em sua constituição fitoquímica substâncias antivirais promissoras, como por exemplo, sementes de Peganum harmala, uma Zygophyllaceae, que in vitro inviabilizou a replicação do vírus da gripe, pela síntese tardia de proteínas virais (Moradi et al., 2017). Diante disso, observa-se que dependendo do tipo de planta, algumas partes desta ou regiões inteiras, são passíveis de serem estudadas e seus princípios bioativos validados, objetivando conhecer substâncias que possam vir a ser utilizadas no combate a doenças virais (Farzaneh e Carvalho, 2015).

Anteriormente, pesquisa com produtos naturais tratava-se de algo intuitivo ou empírico, porém com o tempo os fitocompostos passaram a ser fonte das substâncias onde tem se concentrado o maior número de pesquisas para uso terapêutico em humanos e animais, contra diversas enfermidades infecciosas, sendo que em torno de $30 \%$ das drogas que se tem conhecimento ao redor do mundo são sintetizadas de maneira direta ou indireta de plantas (Dantas et al, 2009; Maia et al., 2015).

A partir dessa premissa, é notório que a diversidade biológica da flora brasileira contribui para o direcionamento das pesquisas para o desenvolvimento de fitoterápicos, incluindo aqueles com potencial ação antiviral, os quais podem vir a serem utilizados na terapêutica humana e veterinária, de maneira alternativa ou complementar, na forma de vegetais frescos, extratos vegetais e especialmente fitocompostos (Simoni, 2011).

A base dos estudos nessa temática são os metabólitos secundários (alcaloides, flavonoides e terpenoides) por exercerem papel fundamental na pesquisa por compostos antivirais bioativos, apresentando resultado promissor para a atividade antiviral de flavonoides isolados ou constituintes de extratos vegetais (Nolkemper et al., 2010; Moradi et al., 2017; Shikalepo et al., 2017). Diversas pesquisas já demonstraram a eficácia de compostos flavonoides exercendo atividade antiviral contra os mais diferentes vírus, inclusive retrovírus, como é o caso do CAEV (Dell'Aica et al., 2004; Wang et al., 2013; Zafar et al., 2013; Adianti et al., 2014; Santos et al., 2014; Zhang et al., 2014), pois certos tipos de flavonoides podem determinar inibição da transcriptase reversa (Ahmad et al., 2015).

Além disso, alguns estudos relataram que fitocompostos com substâncias antioxidantes têm reduzido progressivamente certas retroviroses, como por exemplo, extratos de Carprobrotus edulis (Omoruyi et al., 2012), Plectranthus barbatus (Kapewangolo et al., 2013), e Bulbine frutescens (Shikalepo et al., 2017).

Dentre as principais vantagens da adoção de fitocompostos na medicina veterinária estão o baixo custo, acessibilidade de matéria prima, e riscos mínimos de efeito colateral, por se tratar de um medicamento natural (Farzaneh e Carvalho, 2015). No entanto, os fitoterápicos, bem como as soluções utilizadas no preparo e dissolução dos mesmos, podem ser tóxicos a célula ou ao organismo como todo, que se almeja tratar ou proteger, sendo assim imprescindível realizar ensaios de citotoxicidade a fim de eliminar eventuais efeitos danosos e indesejáveis. Adicionalmente, observa-se que determinadas limitações que são atribuídas ao uso de fitoterápicos, em geral, referem-se à parte da planta selecionada (por poder influenciar na concentração do princípio ativo), estabilização da solução (soluções de fácil degradação) e mensuração das concentrações do princípio ativo (Oliveira et al., 2009).

A grande maioria dos produtos naturais com efeito antiviral descrito na literatura trata-se de extratos aquosos e etanólicos (Parida et al. 2002; Zafar et al., 2013; Adianti et al., 2014; Santos et al., 2014; Zhang et al., 2014). Na dissolução dessas drogas normalmente se opta pelo dimetilsulfóxido (DMSO) como seu principal solvente por ser altamente solúvel e não causar interferência molecular nos componentes fitoquímicos (Bona et al., 2014). Diante disso, torna-se ainda mais viável a busca por uma alternativa antiviral a base de produtos naturais para tratar o sêmen infectado com o CAEV, uma vez que o DMSO, o principal solvente de extratos vegetais, quando presente no diluidor seminal caprino não determina perda na qualidade espermática (Peixoto et al., 2017).

Entretanto, na avaliação da eficácia desses fitoterápicos são passíveis inúmeros métodos de avaliação, porém a ausência de dados científicos que indique qual seria o melhor a ser adotado, associado à falta de padronização da metodologia 
de extração, e consequentemente de análises in vitro, acabam por limitar maiores avanços no ramo das pesquisas com produtos naturais (Bona et al., 2014).

\section{Considerações Finais}

$\mathrm{O}$ crescimento das pesquisas efetuando testes com as mais variadas espécies de plantas já comprovaram que é possível encontrar constituintes fitoquímicos com efeito antiviral, inclusive contra um retrovírus, mesmo fazendo uso da extração dos constituintes via processo aquoso ou etanólico, com dissolução em DMSO. E, adicionalmente, a classe de metabólitos secundários se concretiza como a fonte de onde pode se conseguir alternativas eficazes no combate às doenças de caráter viral, visando no caso dos retrovírus a atingir principalmente a transcriptase reversa.

Nesse contexto, espera-se que essas plantas possam também se tornar eficazes na inativação do CAEV presente no sêmen de reprodutores caprinos, sem causar danos à célula espermática e nem interferência na fertilidade, possibilitando assim o uso de material genético advindo de reprodutor infectado pelo lentivírus caprino. No entanto, como forma de incentivo é imprescindível que metodologias sejam padronizadas e parcerias interdisciplinares formalizadas com a perspectiva de explorar com racionalidade e sustentabilidade a rica biodiversidade, especialmente, da flora brasileira.

\section{Agradecimentos}

À Coordenação de Aperfeiçoamento de Pessoal de Nível Superior (CAPES) pela concessão da bolsa de estudo; à Embrapa Caprinos e Ovinos pelo apoio e suporte técnico; e à Universidade Estadual do Ceará (UECE) pela disponibilização do Laboratório de Virologia e Laboratório de Química de Produtos Naturais.

\section{Referências}

Adianti, M.; Aoki, C.; Komoto, M.; Deng, L.; Shoji, I.; Wahyuni, T.S.; Lusida, M.I.; Soetjipto; Fuchino, H.; Kawahara, N.; Hotta, H. Antihepatitis $\mathrm{C}$ virus compounds obtained from Glycyrrhiza uralensisand other Glycyrrhiza species. Microbiology and Immunology, 58(3): 180-187, 2014.

Ahmad, A.; Kaleem, M.; Ahmed, Z.; Shafiq, H. Therapeutic potential of flavonoids and their mechanism of action against microbial and viral infections - A review. Food Research International, 77: 221-235, 2015.

Al Ahmad, M.Z.; Fieni, F.; Pellerin, J.L.; Guiguen, F.; Cherel, Y.; Chatagnon, G. Detection of viral genomes of caprine arthritis-encephalitis virus (CAEV) in semen and in genital tract tissues of male goat. Theriogenology, 69: 473-480, 2008.

Al-Hashemi, Z.S.S.; Hossain, M.A. Biological activities of different neem leaf crude extracts used locally in Ayurvedic medicine. Pacific Science Review A: Natural Science and Engineering, 18: 128-131, 2016.

Arthanari, S.K.; Vanitha, J.; Ganesh, M.; Venkateshwaran, K.; Clercq, D. Evaluation of antiviral and cytotoxic activities of methanolic extract of $S$. grandiflora (Fabaceae) flowers. Asian Pacific Journal of Tropical Biomedicine, 855-858, 2012.

Ávila, A.A.; Sider, L.H.; Veras, A.K.A.; Pinheiro, R.R.; Oliveira, M.L.M.; Silva, P.A.F.; Sousa, S.D.; Andrioli, A. Uso da técnica de swim-up para a remoção do vírus da artrite encefalite caprina do sêmen de reprodutores infectados. Arquivo Brasileiro de Medicina Veterinária e Zootecnia, 67(1): 94-102, 2015.

Auta, T.: Hassan, A.T. Reproductive toxicity of aqueous wood-ash extract of Azadirachta indica (neem) on male albino mice. Asian Pacific Journal of Reproduction, 5(2): 11115, 2016.

Bagla, V.P.; McGaw, L.J.; Eloff, J.N. The antiviral activity of six South African plants traditionally used against infections in ethnoveterinary medicine. Veterinary Microbiology, 155: 198206, 2012.

Bang, S.; Ha, T.K.Q.; Lee, C.; Li, W.; Oh, W.; Shim, S.H. Antiviral activities of compounds from aerial parts of Salvia plebeian $\mathrm{R}$. Br. Journal of Ethnopharmacology, 192: 398405, 2016.

Beula, J.M.; Granadesigan, M.; Rajkumar, P.B.; Ravikumar, S.; Anand, M. Antiviral, antioxidante and toxicological evaluation of mangrove plant from South East coast of India. Asian Pacific Journal of Tropical Biomedicine, 352-357, 2012.

Bona, E.A.M.; Pinto, F.G.S.; Fruet, T.K.; Jorge, T.C.M.; Moura, A.C. Comparação de métodos para avaliação da atividade antimicrobiana e determinação da concentração inibitória mínima (cim) de extratos vegetais aquosos e etanólicos. Arquivo do Instituto Biológico, 81(3): 218-225, 2014. 
Bueno, C.A.; Lombardi, M.G.; Sales, M.E.; Alché, L.E. A natural antiviral and immunomodulatory compound with antiangiogenic properties. Microvascular Research, 84: 235-241, 2012.

CBRA - Colégio Brasileiro de Reprodução Animal. Manual para exame andrológico e avaliação de sêmen animal. $2^{\mathrm{a}}$ ed. Belo Horizonte: CBRA, 2013. 49p.

Cortez-Romero, C.; Pellerinm J.L.; Ali Al Ahmad, M.Z.; Chebloune, Y.; Gallegos-Sanchez, J.; Lamara, A.; Pépin, M.; Fieni, F. The risk of small ruminant lentivirus (SRLV) transmission with reproductive biotechnologies: State-ofthe-art review. Theriogenology, 79: 1-9, 2013.

Dan, G.; Castellar, A. Plantas medicinais com atividade antirretroviral. Alumni, 3(6): 1-17, 2015.

Dantas, S.A.F.; Sena, L.V.T.; Melo, D.J.A.; Duarte, F.T.; Carvalho, A.S. Avaliação de plantas medicinais no combate a mastite bovina. Holos, 4: 2009.

Dell'Aica, I.; Dona, M.; Tonello, F.; Piris, A.; Mock, M.; Montecucco, C.; Garbisa, S. Potent inhibitors of anthrax lethal factor from green tea. EMBO Reports, 5(4): 418-422, 2004.

Faccin-Galhardi, L.C.; Yamamoto, K.A.; Ray, S.; Ray, B.; Linhares, R.E.C.; Nozawa, C. The in vitro antiviral property of Azadirachta indica polysaccharides for poliovirus. Journal of Ethnopharmacology, 142: 86-90, 2012.

Farzaneh, V.; Carvalho, I.S. A review of the health benefit potentials of herbal plant infusions and their mechanism of actions. Industrial Crops and Products, 65: 247-258, 2015.

Feng, H.; Fan, J.; Yang, S.; Zhao, X.; Yi, X. Antiviral activity of phosphorylated Radix Cyathulae officinalis polysaccharide against Canine Parvovirus in vitro. International Journal of Biological Macromolecules, 99: 511-518, 2017.

Glatthaar-Saalmüller, B.; Fal, A.M.; Schönknecht, K.; Conrad, F.; Sievers, H.; Saalmüller, A. Antiviral activity of an aqueous extract derived from Aloe arborescens Mill. Against a broad panel of viruses causing infections of the upper respiratory tract. Phytomedicine, 22: 911-920, 2015.

Gu, S.X.; Xue, P.; Ju, S.L.; Zhu, Y.Y. Advances in rationally designed dual inhibitors of HIV-1 reverse transcriptase and integrase. Bioorganic \& Medicinal Chemistry, 24: 5007-5016, 2016. Ha, T.K.Q.; Dao, T.T.; Nguyen, N.H.; Kim, J.; Kim, E.; Cho, T.O.; Oh, W.K. Antiviral phenolics from the leaves of Cleistocalyx operculatus. Fitoterapia, 110: 135-141, 2016.

Helfer, M.; Koppensteiner, H.; Schneider, M.; Rebensburg, S.; Forcisi, S.; Müller, C.; Schimitt-Kopplin, P.; Schindler, M.; BrackWerner, R. The root extract of the medicinal plant Pelargonium sidoides is a potent HIV-1 attachment inhibitor. Plos One, 9(1): 1-12, 2014.

Kapewangolo, P.; Tawha, T.; Nawinda, T.; Knott, M.; Hans, R. Sceletium tortuosum demonstrates in vitro anti-HIV and free radical scavenging activity. South African Journal of Botany, 106: 140-143, 2013.

ICTV. International Committee on Taxonomy of Viruses. Virus Taxonomy: 2013. Disponível em: <http: //ictvonline.org/virusTaxonomy.asp>. Acesso em: 28 set. 2017.

Kenyon, J.C.; Lever, A.M. The molecular biology of feline immunodeficiency virus. Viruses, 3(11): 2193-2213, 2011.

Kim, H.; Kwon, H.; Ryu, Y.B.; Chang, J.S.; Cho, K.; Hosmillo, M.D.T.; Rho, M.; Park, S.; Lee, W.S. Antiviral activity of Alpinia katsumadai extracts against rotaviruses. Research in Veterinary Science, 92: 320-323, 2012.

Khillare, B.; Shrivastav, T.G. Spermicidal activity of Azadirachta indica (neem) leaf extract. Contraception, 68: 225-229, 2003.

Kumazawa, S.; Kubota, S.; Yamamoto, H.; Okamura, N.; Sugiyamab, Y.; Kobayashia, H.; Nakanishi, M.; Ohta, T. Antiangiogenic activity of flavonoids from Melia azedarach. Natural Product Communications, 8(12): 1719-120, 2013.

Lamara, A.; Fieni, F.; Chatagnon, G.; Larrat, M.; Dubreil, L.; Chebloune, Y. Caprine arthritis encephalitis virus (CAEV) replicates productively in cultured epididymal cells from goats. Comparative Immunology, Microbiology and Infectious Diseases, 36: 397-404, 2013.

L'Homme, Y.; Leboeuf, A.; Arsenault, J.; Fras, M. Identification and characterization of an emerging small ruminant lentivirus circulating recombinant form (CRF). Virology, 475: 159171, 2015.

Lin, L.; Hsu, W.; Lin, C. Antiviral natural products and herbal medicines. Journal of Traditional and Complementary Medicine, 4(1): 24-35, 2014. 
Maia, T.F.; Donato, A.; Fraga, M.E. Atividade antifúngica de óleos essenciais de plantas. Revista Brasileira de Produtos Agroindustriais, 17(1): 105-116, 2015.

Ministério da Saúde. Formulário terapêutico nacional 2008: Rename 2006. $1^{\text {a }}$ ed. Brasília: Ministério da Saúde, 2008. 897p.

Minguijón, E.; Reina, R.; Pérez, M.; Polledo, L.; Villoria, M.; Ramírez, H.; Leginagoikoa, I.; Badiola, J.J.; García-Martín, J.F.; De Andrés, D.; Luján, L.; Amorena, B.; Juste, R.A. Small ruminant lentivirus infections and diseases. Veterinary Microbiology, 181(1): 75-89, 2015.

Mophuting, B.C.; Bapela, M.J.; Tshikalange, T.E. In vitro antigonococcal, anti-inflammatory and HIV-1 reverse transcriptase activities of the herbal mixture used for the treatment of sexually transmitted diseases. South African Journal of Botany, 109: 354-255, 2017.

Moradi, M.; Karimi, A.; Rafieian-Kopaei, M.; Fotouhi, F. In vitro antiviral effects of Peganum harmala seed extract and its total alkaloids against Influenza virus. Microbial Pathogenesis, 110: 42-49, 2017.

Ngwira, K.J.; Maharaj, V.J.; Magani, Q.A. In vitro antiplasmodial and HIV-1 neutralization activities of root and leaf extracts from Berberis holstii. Journal of Herbal Medicine, 5: 30-35, 2015.

Nolkemper S.; Reichling, J.; Sensch, K.H.; Schnitzlu, P. Mechanism of herpes simplex virus type 2 suppression by propolis extracts. Phytomedicine, 17: 131-148, 2010.

Oliveira, M.C.S.; Giglioti, R.; Forim, M.R.; Calura, F.H.; Oliveira, H.N.; Chagas, A.C.S.; Brito, L.G. Uso de extratos de Nim (Azadirachta indica) no controle de carrapato Rhipicephalus (Boophilus) microplus. São Carlos: Embrapa Pecuária Sudeste, 2009. 12p. Comunicado Técnico, 90.

Omoruyi, B.E.; Bradley, G.; Afolayan, J.A. Antioxidant and phytochemical properties of Carpobrotus edulis (L.) bolus leaf used for the management of common infections in HIV/AIDS patients in Eastern Cape Province. BMC Complementary and Alternative Medicine, 12: 1-9, 2012.

Parida, M.M.; Upadhyay, C.; Pandya, G.; Jana, A.M. Inhibitory potential of neem (Azadirachta indica Juss) leaves Dengue virus type-2 replication. Journal of Ethnopharmacology, 79: 273-278, 2002.
Paula, N.R.O.; Andrioli, A.; Cardoso, J.F.S.; Pinheiro, R.R.; Sousa, F.M.L.; Souza, K.C.; Alves, F.S.F.; Campello, C.C.; Ricarte, A.R.F.; Teixeira, M.F.S. Profile of the Caprine arthritisencephalitis virus (CAEV) in blood, semen from bucks naturally and experimentally infected in the semi-arid region of Brazil. Small Ruminant Research, 85(1): 27-33, 2009.

Peixoto, R.M.; Andrioli, A.; Santos, D.O.; Pinheiro, R.R.; Araújo, J.F.; Sousa A.L.M.; Silva, D.F.; Damasceno, E.M.; Teixeira, M.F.S. Avaliação da toxicidade de solvente de extratos vegetais com ação antiviral em sêmen caprino refrigerado. Acta Scientiae Veterinariae, 45: 1-8, 2017.

Peterson, K.; Brinkhof, J.; Houwers, D.J.; Colenbrander, B.; Gadella, B.M. Presence of pro-lentiviral DNA in male sexual organs and ejaculates of small ruminants. Theriogenology, 69: 433-442, 2008.

Petrera, E.; Coto, C.E. Therapeutic effect of meliacine, an antiviral derived from Melia azedarach L., in mice genital herpetic infection. Phytotherapy Research, 23: 1771-1777, 2009.

Prinsloo, G.; Marokane, C.K.; Street, R.A. AntiHIV activity of southern African plants: Current developments, phytochemistry and future research. Journal of Ethnopharmacology, 210: 133-155, 2017.

Rebensburg, S.; Helfer, M.; Schneider, M.; Koppensteiner, H.; Eberle, J.; Schindler, M.; Gürtler, L.; Brack-Werner, R. Potent in vitroantiviral activity of Cistus incanus extract against HIV and Filoviruses targets viral envelope proteins. Scientific Reports, 6:1-15, 2016.

Ricarte, A.R.F.; Andrioli, A.; Pinheiro, R.R.; Báo, S.N.; Silva, J.S.; Braz, S.V.; Name, K.P.O.; Lima-Verde, I.B.; Brito, I.F.; Dias, R.P.; Aguiar, T.D.; Dantas, T.V.M.; Araújo S.A.C.; Cavalcanti, D.M.L.P.; Paula, N.R.O.; Teixeira, M.F.S. Avaliação imunohistoquímica e ultraestrutural de gametas e embriões caprinos infectados com o CAEV. Arquivo do Instituto Biológico, 77(2): 217-223, 2010.

Santos, A.E.; Kuster, R.M.; Yamamoto, K.A.; Salles, T.S.; Campos, R.; Meneses, M.D.; Soares, M.R.; Ferreira, D. Quercetin and quercetin 3-O-glycosides from Bauhinia longifolia (Bong.) Steud. show anti-Mayaro virus activity. Parasites and Vectors, 7(1): 130, 2014. 
Seo, D.J.; Lee, M.; Jeon, S.B.; Park, H.; Jeong, S.; Lee, B.; Choi, S. Antiviral activity of herbal extracts against the hepatitis A virus. Food Control, 72: 9-13, 2017.

Simoni, I. Plantas com poder curativo na saúde animal. Instituto Biológico, 155, 2011.

Shikalepo, R.; Mukakalisa, C.; Kandawa-Schulz, M.; Chingwaru, W.; Kapewangolo, P. In vitro anti-HIV and antioxidant potential of Bulbine frutescens (Asphodelaceae). Journal of Herbal Medicine, 1-6, 2017.

Silva, F.S.; Silva, D.S.; Vargas, G.D.; Fischer, G.; Lima, M.; Húbner, S.O. Terapia antirretroviral no controle da infecção pelo vírus da imunodeficiência felina: revisão e perspectivas. Science and Animal Health, 4(3): 268-282, 2016.

Song, X.; Yin, Z.; Li, L.; Cheng, A.; Jia, R.; Xu, J.; Wang, Y.; Yao, X.; Lv, C.; Zhao, X. Antiviral activity of sulfated Chuanminshen violaceum polysaccharide against duck enteritis virus in vitro. Antiviral Research, 98: 344-351, 2013.

Song, X.; Zhang, Y.; Yin, Z.; Zhao, X.; Liang, X.; He, C.; Yin, L.; Lv, C.; Zhao, L.; Ye, G.; Shi, F.; Shu, G.; Jia, R. Antiviral effect of sulfated Chuanmingshen violaceum polysaccharide in chickens infected with virulent Newcastle disease virus. Virology, 476: 316-322, 2015.

Souza, K.C.; Pinheiro, R.R.; Santos, D.O.; Brito, R.L.L.; Rodrigues, A.S.; Sider, L.H.; Paula, N.R.O.; Ávila, A.A.; Cardoso, J.F.S.; Andrioli A. Transmission of the caprine arthritisencephalitis virus through artificial insemination. Small Ruminant Research, 109: 193-198, 2013.

Souza, K.C.; Andrioli, A.; Teixeira, M.F.S. Vírus da artrite encefalite caprina em sêmen: diagnóstico e transmissão. Revista Brasileira de Reprodução Animal, 38(2) : 92-97, 2014.

Travassos, C.E.; Benôit, C.; Valas, S.; Silva, A.G.; Perrin, G. Detection of caprine arthritisencephalitis virus in semen of naturally infected bucks. Small Ruminant Research, 32: 101106, 1999.

Twilley, D.; Langhansová, L.; Palaniswamy, D.; Lall, N. Evaluation of traditionally used medicinal plants for anticancer, antioxidant, anti-inflammatory and anti-viral (HPV-1) activity. South African Journal of Botany, 112: 494-500, 2017.

Turchetti, A.P. ; Paniago, J.J. ; Costa, L.F. ; Cruz, J.C. ; Braz, G.F. ; Gouveia, A.M. ; Paixão,
T.A. ; Santos, R.L. ; Heinemann, M.B. Distribution of caprine arthritis encephalitis vírus provirus, RNA, and antigen in the reproductive tract of one naturally and seven experimentally infected bucks. Theriogenology, 80: 933-939, 2013.

Tu, P.A., Shiu, J.S.; Lee, S.H.; Pang, V.F.; Wang, D.C.; Wang, P.H. Development of a recombinase polymerase amplification lateral flow dipstick (RPA-LFD) for the field diagnosis of caprine arthritis-encephalitis virus (CAEV) infection. Journal of Virological Methods, 243: 98-104, 2017.

Wang, H.Q.; Meng, S.; Li, Z.R.; Peng, Z.G.; Han, Y.X.; Guo, S.S.; Cui, X.L.; Li, Y.H.; Jiang, J.D. The antiviral effect of 7-hydroxyisoflavone against Enterovirus 71 in vitro. Journal of Asian Natural Products Research, 15(4): 382-389, 2013.

Yeh, R.W.; Coen, D.M. Farmacologia das infecções virais. In: Golan, D.E.; Tashjian, J.R.; A.H.; Armstrong, E.J.; Armstrong, A.W. (ed.). Principles of pharmacology: The pathophysiologic basis of drug therapy. $3^{\text {rd }}$ ed. Philadelphia: Deputy editor, 2011. p.609630.

Yeh, C.H.; Chang, J.S.; Wang, K.C..; Shieh, D.E.; Chiang, L.C. Water extract of Cinnamomum cassia blume inhibited human respiratory syncytial virus by preventing viral attachment, internalization, and syncytium formation. Journal of Ethnopharmacology, 147: 321326, 2013.

Zafar, M.S.; Muhammad, F.; Javed, I.; Akhtar, M.; Khaliq, T.; Aslam, B.; Waheed, A.; Yasmin, R.; Zafar, H. Mulberry (Morus alba): A brief phytochemical and pharmacological evaluations account. International Journal of Agriculture and Biology, 15: 612-620, 2013.

Zhang, W.; Quiao, H.; Lv, Y.; Wang, J.; Chen, X.; Hou, Y.; Tan, R.; Li, E. Apigenin inhibits enterovirus-71 infection by disrupting viral RNA association with trans-acting factors. Plos One, 9(10): 1-9, 2014.

Zhang, X.; Xia, Q.; Yang, G.; Zhu, D.; Shao, Y.; Zhang, J.; Cui, Y.; Wang, R.; Zhang, L. The anti-HIV-1 activity of polyphenols from Phyllanthus urinaria and the pharmacokinetics and tissue distribution of its marker compound, gallic acid. Journal of Traditional Chinese Medical Sciences, 1-9, 2017. 